\title{
Structural Models of Complementary Choices
}

\section{Citation}

Berry, Steven T., Ahmed Khwaja, Vineet Kumar, Andres Musalem, Kenneth C. Wilbur, Greg Allenby, Bharat Anand, et al. "Structural Models of Complementary Choices." Marketing Letters 25, no. 3 (September 2014): 245-256.

\section{Published Version}

doi:10.1007/s11002-014-9309-y

\section{Permanent link}

http://nrs.harvard.edu/urn-3:HUL.InstRepos:14010993

\section{Terms of Use}

This article was downloaded from Harvard University's DASH repository, and is made available under the terms and conditions applicable to Open Access Policy Articles, as set forth at http:// nrs.harvard.edu/urn-3:HUL.InstRepos:dash.current.terms-of-use\#OAP

\section{Share Your Story}

The Harvard community has made this article openly available.

Please share how this access benefits you. Submit a story.

Accessibility 


\section{Structural Models of Complementary Choices}

Steve Berry, co-chair (Economics, Yale University)

Ahmed Khwaja, co-chair (Marketing, School of Management, Yale University)

Vineet Kumar, co-chair (Marketing, Harvard Business School)

Andres Musalem, co-chair (Marketing, Duke University)

Kenneth C. Wilbur, co-chair (Marketing, UC-San Diego)

Greg Allenby (Marketing, Ohio State University)

Bharat Anand (Strategy, Harvard Business School)

Pradeep Chintagunta (Marketing, Booth School, University of Chicago)

W. Michael Hanemann (Agricultural \& Resource Economics, UC Berkeley)

Przemek Jeziorski (Marketing, Haas School, UC Berkeley)

Angelo Mele (Carey Business School, Johns Hopkins University) 


\section{Introduction}

Complementary choices are important and pervasive yet occasionally elusive. Single consumers make complementary choices in purchase decisions (e.g. chips and salsa), product inter-operabilities (smartphones and networks), and dynamic decisions (current exercise and future healthcare consumption). Multiple consumers make complementary choices when they interact in strategic games or form networks. Firms make complementary choices when determining production inputs, entering related markets, and strategic mergers.

The structural empirical literature has recently started to address the difficult problem of how to model complementary choices. This new work contrasts with traditional approaches such as discrete choice models, wherein all choices are mutually exclusive.

A naïve approach to modeling complementary choices is to include all possible bundles of choices in the choice set. However, for any given set of options, the set of all possible subsets is exponentially larger, and often too large to feasibly estimate. Second, specific models of complementarities are needed to ensure desirable equilibrium properties in games among agents (e.g., existence, uniqueness or multiplicity). Third, models of complementarities are often required to evaluate counterfactuals, such as predicting demand for bundles of complementary products that have not previously been offered.

We review the literature selectively, summarizing the state of the art and identifying promising directions for future work. We begin with complementary choices made by consumers, and then examine complementary choices made by firms.

\section{Demand Complementarities.}

Complementary goods are defined using two subtly different approaches, both based on the idea of a positive interaction between the goods. Milgrom and Roberts (1990) defined complements occurring when consumer utility functions are supermodular in their arguments, i.e. for two $\mathrm{N}$-dimensional vectors of complementary goods $x=\left(x_{1}, \ldots, x_{N}\right)$ and $x^{\prime}=\left(x_{1}{ }^{\prime}, \ldots, x_{N}{ }^{\prime}\right)$, a smooth utility function satisfies:

$$
u(x)-u\left(x^{\prime}\right) \geq \sum_{i}\left[u\left(x_{i}, x_{-i}^{\prime}\right)-u\left(x^{\prime}\right)\right]
$$

With smooth utility functions, this definition is equivalent to positive cross-partial derivative of utility with respect to quantities. ${ }^{1}$

The textbook definition of complements is based on negative cross-price elasticity of demand between two goods, i.e. an increase in the price of one good will result in a decrease in demand for

\footnotetext{
${ }^{1}$ A related definition based on super-additivity comes from Brandenburger-Nalebuff (2011). It defines complementarity as: value from product $\mathrm{A}$ increases with availability of product B.
} 
the other (i.e. a positive cross-partial derivative of Hicksian demand). This definition may arise from a single-agent model or a theoretical characterization of aggregate demand.

Demand-side complements fall into the following non-exclusive categories:

1. Quantity complements: Higher quantity of one product leads to higher value for another, e.g. left shoes and right shoes.

2. Quality complements: Higher quality of one product leads to higher marginal value of quality for another, e.g. a suit paired with a tie.

3. Within-category complements: The value of a portfolio of related products is the option value of consuming the best fit to current needs, e.g. a home movie library.

4. Cross-category complements: When products are materially combined to obtain higher consumer value, e.g. milk and cereal, hardware and software, etc.

5. Provider-driven Complementarity: Independent products become complements when provided by a single firm due to brand or service delivery spillovers, e.g. banking and investments.

6. Dynamic Complements: Choices that are substitutes in static settings can become complements in a dynamic setting, e.g. different seasons of a television show.

7. Complementarities across Individual Agents: When agents interact, their choices may be complementary, e.g. the decision to form a relationship must be mutually chosen.

We begin with the categories that have been studied most frequently (1-5), those describing complementarities choices made by an individual decision-maker. We then consider complementary choices over time (category 6) and choices made by multiple agents (category 7).

\subsection{Single-Agent, Static Choices}

Canonical examples of complements include jointly consumed products such as detergent and softener or chips and salsa. Estimating complementarities in aggregate demand dates back, at least, to Sato (1967), who specified a multi-level constant elasticity of substitution model and applied it to aggregate data. Causal inference is typically more difficult with aggregate data: if demand for detergent and softener are found to be positively correlated, is that because they are complementary or because demand for each product is positively related to some unobserved variable?

Most papers that have estimated complementarities using individual level data have extended the indirect utility models underlying traditional choice models, reviewed in Manchanda et al. (1999). This approach relates the purchase incidence of a product in one category to purchases of other products in other categories, e.g. if a consumer is more likely to buy detergent, then she may also be more likely to buy softener during that shopping trip. However, these indirect utility models typically do not specify the corresponding direct utility structure, making the assumptions about consumer preferences unclear. For example, the indirect utility function that is taken to the data might not exhibit such basic properties as homogeneity of degree zero in prices and income or quasi-convexity in prices and income.

A smaller stream of literature has derived individual-level models of complementary choices from first principles (e.g., Kim et al. 2002, Chan 2006, Gentzkow 2007, Bhat 2008, Vásquez and 
Hanemann 2008, Bhat and Pinjari 2010, Musalem et al. 2013). These models rely on classical economic choice theory, usually assuming that each agent maximizes a linearly additive utility function subject to a budget constraint. Applications of these models face the following primary challenges: (i) modeling both purchase incidence and quantities for multiple choices, (ii) large choice sets, (iii) determining the set of complementary goods, and (iv) balancing model flexibility and parsimony.

\section{Multiple Goods and Quantities}

Complementary choices may lead consumers to purchase multiple varieties of multiple goods; for example, a consumer might buy several different jars of salsa and multiple bags of chips. Traditional choice models focused on whether or not the consumer made a purchase, which Hanemann (1984) extended to incorporate quantity choice.

The direct utility approach is particularly well suited for estimating positive quantities demanded of multiple goods, because each good is associated with its own first-order condition. If utility remains quasiconcave, it is desirable to allow demand for two complementary goods to be interrelated through their purchased quantities. For example, buying more chips would increase demand for salsa. Thus, we should model not only incidence but also purchase quantity (e.g., Kim et al. 2002). For example, Lee and Allenby (2013) showed how to incorporate discrete package sizes into a direct utility model. Most consumer product categories admit only a few different package sizes; for example, in the US beer market, the most common options for beer are 40, 72 or 144 fluid ounces.

\section{Large Choice Sets}

A second challenge is associated with the dimensionality of the dataset. When estimating demand at the individual level, the size of the dataset scales with the number of consumers, choice occasions and options. Therefore, datasets may easily contain tens or hundreds of millions of choices.

Moreover, choice datasets are overwhelmingly comprised of zeros (i.e., non-chosen alternatives). Therefore, our demand models must allow for corner solutions. In direct utility models, Kuhn-Tucker conditions lead to inequality constraints on utility shocks of non-chosen goods. If an agent does not choose an alternative, then marginal utility must be small, giving an upper bound inequality on the associated error. These inequalities provide a mass-contribution to the model likelihood as opposed to interior points that lead to a density contribution to the likelihood (Satomura, et al., 2011). Moment inequalities might be a promising approach here (Pakes, 2010, Figurelli, 2012). Broadly, improving the computational efficiency of such models remains a promising direction for future research

\section{Determining the set of interrelated goods.}

Most of the literature identifies complementary choices a priori, with data used to measure degree of complementarity. When unexpected complementarities drive purchases, can we devise models that can easily test for the presence of hidden complementarities? A crucial challenge is that the number of complementarities grows in the number of product pairs, i.e. $\mathrm{N}$ goods admit $\mathrm{N}(\mathrm{N}-1)$ possible 
pairwise complementarities. Currently, institutional knowledge typically restricts the set of possible complementarities, but tractable approaches to estimating complementarities would be helpful.

\section{Modeling Challenges}

The basic identification logic requires that the likelihood of choosing $\mathrm{B}$ depends on whether $\mathrm{A}$ is chosen, or whether the individual has chosen A in the past (inventory). Berry, Gandhi and Haile (2011) established the nonparametric identification of a continuous demand system when differentiated products are substitutes, but only for limited cases with complementarities. Establishing identification remains a technically challenging problem but is a critically important direction for future work.

Individual level choice data is typically shallow but broad, with a small (e.g., $<15$ ) number of choice occasions per respondent. Choice attributes such as prices, package sizes and merchandising variables change across shopping visits, requiring models that can reconcile individual-level response to these variables. Disaggregate demand models require large datasets to reliably estimate flexible models of the relationship among varieties (Allenby et al. 2005). Low-dimensional restrictions, such as allowing complementary behavior only through summary variables (e.g., category inventory), reduce the number of parameters. Furthermore, small-sample inference, coupled with discrete demand, lends itself to the use of Bayesian estimation methods (Rossi et al. 2005). Data augmentation is particularly helpful in dealing with discontinuities in demand space (Lee and Allenby 2013).

To estimate complementarities in a general form, direct utility models need to be extended, potentially leading to a curse of dimensionality, where the number of parameters to be estimated grows faster than data. This problem arises in the models of Gentzkow (2007), Song and Chintagunta (2007), Vásquez and Hanemann (2008) and Bhat and Pinjari (2010) and suggests a need for approaches that allow us to parsimoniously model these interrelations.

A "summary statistic" approach is to capture the interaction by modeling the utility of one good, e.g., a salsa brand, as a function of the total inventory of goods from a complementary category, e.g., all brands of chips (Lee, Kim and Allenby, 2013). Thus, a consumer who has a large inventory of different brands of chips might feel compelled to buy more salsa. Complementary choices can involve more than two categories. Sriram et al. (2010) characterize three related technologies, PCs, Printers and Digital Cameras, modeling and identifying complementarities by aggregating all products within a category, focusing on cross-category complementarities.

Another approach is to rely on weak separability (Musalem et al., 2013). Goods are grouped into subsets. The marginal utility of each product depends on the quantity consumed of the other products within the subset. However, goods belonging to different subsets are only related through the budget constraint. For example, considering four types of goods, one subset might be \{chips,salsa\}, and another \{detergent,softener\}.

Finally, the demand for a good may depend, not only on quantity, but also product attributes of another good, e.g. purchase of detergent might depend on active ingredients, rather than brand, of the 
softener. Formulating a model that allows attribute complementarities is an important direction for future work.

\subsection{Single-Agent Dynamic Choices}

Dynamics often reveal additional insights about complementary choices. Key challenges in designing dynamic models include: complementarities between sequential choices, changes from substitutes to complements, and dynamic complementarities between past/future purchases.

\section{Choice Sequences}

In technology, complementary products are purchased in sequence, e.g. consumers first buy a smartphone and then apps. The first choice determines the consumer's choice set for the second, with complementarities between these creating "lock-in." Derdenger et al. (2013) develop a dynamic framework of complementarities between compatible products, wherein intertemporal choice dependencies are driven by consumer inventory of products and accessories (e.g. digital cameras and memory cards).

Choice sequences arise in many other contexts, e.g., TV channels offer programs exhibiting complementarities across episodes. A robust pattern in TV viewership is network loyalty, deriving from viewer preferences (together with correlation in networks' offerings), viewer switching costs, cross-promotional effects, and viewer uncertainty about program characteristics. Anand and Shachar (2006, 2011) exploited individual level viewer and advertising exposure data to disentangle these different reasons for loyalty, with implications for programming, scheduling and umbrella brand portfolio decisions.

Healthcare also involves sequential complementary decisions. Lifestyle choices affect consumers' health, complementing choices of health insurance and medical care. An individual's health status, partially observable to the researcher, connects these choices (Khwaja 2010). Moral hazard and selection influence these choices, resulting in inter-temporal trade-offs. Khwaja (2013) estimates a model of repeated sequential decisions regarding health insurance, medical treatment and health related consumption. Health status is a serially persistent variable that can accumulate or depreciate due to individual choices, leading to endogenous longevity. The "Mickey Mantle" effect of longevity on consumption and behaviors is seen, i.e., increasing life expectancy decreases consumption of harmful products. ${ }^{2}$

A related challenge is the time scale of complementarities in choices. Huang et al. (2012) examine individuals balancing long run health goals with complementary short run consumption decisions, which occur at different time scales. Using beverage consumption, activity and psychological needs data, they estimate a model of high frequency consumption choices with intra-day changes in shortrun needs and unobserved heterogeneity across individuals. The analysis provides insights for new product introduction.

\footnotetext{
${ }^{2}$ Mickey Mantle (1931-95, NY Yankees first baseman) famously remarked in his 60s, "If I knew I was going to live this long, I'd have taken better care of myself."
} 


\section{Dynamics Can Turn Substitutes into Complements}

Dynamic settings often reveal hidden complementarities. For instance, Lee et al. (2013) examined how a firm should design product quality in the "freemium" setting, studying consumer decisions using data from a file hosting service. A dynamic perspective revealed complementarity between free and paid versions, as consumers first use the free version of the product, and later upgrade to premium. Therefore, the free version increased long-run sales of the premium service, showing that "static substitutes" can become "dynamic complements."

\subsection{Multi-Agent Choices}

Complementary choices are encountered when there are network effects. In the early literature, the payoff of a choice depended on the fraction of the population choosing the same action (see Shy 2011), e.g. likelihood of adoption depends on the user base. This modeling framework is simple, because the interaction is modeled as a one-dimensional object. More recent literature explicitly models the networks among players: the payoff of an action depends on others' actions within the local network. Early empirical models recognized identification issues (Manski 1993, Bramoulle et al. 2009), including endogeneity of the connections. When the network formation is not modeled, the estimated network effects are biased due to homophily (Badev, 2013; Goldsmith-Pinkham and Imbens, 2013).

The formation of referral networks among physicians, or creation of social relationships in Facebook involve complementary choices: the utility of each agent's choices depends on the number and types of other agents participating. Choosing to form a link requires active choices made by both agents who share the link, and benefit from both direct and indirect connections, implying strategic complementarity. Some key challenges when studying demand complementarities in networks include defining a theoretically founded modeling framework and identification of structural parameters (Jackson 2008).

Structural network formation models suffer from a curse of dimensionality: the number of possible network configurations increases exponentially with the number of players, posing severe challenges to structural estimation. The likelihood in these models involves high-dimensional integration over all possible networks (Mele, 2013) or matchings (Imbens et al., 2010). Estimation interleaves parameter and network simulations to avoid the high-dimensional integration, allowing tractable estimation with myopic agents. ${ }^{3}$ Alternative approaches develop consistent estimators based on asymptotic approximations for large networks (Chandrasekhar and Jackson 2013), or focus on partial identification and set estimation (Miyauchi 2012, De Paula et al. 2011). Pairwise stability of the network reduces the curse of dimensionality because it allows estimation using sub-networks (Sheng 2012). Leung (2013) developed a two-step estimator for a game of network formation. Badev (2013), Hsieh and Lee (2013) and Goldsmith-Pinkham and Imbens (forthcoming) provide the first attempts to study the endogenous network formation and decisions of connected individuals.

\section{Supply Complementarities.}

\footnotetext{
${ }^{3}$ Similar methods for dynamic discrete choice models include Ching et al. (2009) and Norets (2009).
} 


\section{Implications of demand complementarities}

In contrast to notions of "core competence" that lead firms to narrower focus, demand-side complementarities encourage an expansive mindset toward firms' portfolios and boundaries, e.g. tire manufacturers were early investors in paved roads (Brandenburger and Nalebuff, 2011). Demandside complementarities have implications for pricing decisions such as "when" and "where" to make money (e.g. razor/blades or iPod/iTunes pricing), firm boundary decisions, product portfolio choices, umbrella brand strategies, and entry decisions (e.g. new versions).

Bundling, theoretically explored in static settings with non-additive valuations by Armstrong (2013), is an important strategy that requires knowledge of complementarities. In a dynamic context, bundling can enable better segmentation and price discrimination. Derdenger and Kumar (2013) found video game bundling ineffective in dynamic settings because it did not allow for intertemporal sorting of consumers. Further, based on intertemporal variation in the tying ratio (average software units per hardware owned), they identified the correlation of utility between two product categories with multiple sequential purchases, e.g., hardware followed by a library of software purchases.

\section{Complementarities between firm activities}

Complementarities are related to long-standing theories of "fit" in business strategy, revived by Milgrom and Roberts (1990) and Porter (1996). Consider Walmart's unique set of complementary choices: (i) rural store locations (reducing head-to-head competition with rivals); (ii) fully-owned warehousing/distribution centers; (iii) information technology; (iv) and "every-day-low-pricing." Although one activity may be easy for rivals to mimic, copying the full set of complementary activities is harder, effectively creating "barriers to imitation." Complementarities can therefore explain persistent performance differences between firms ("sustainable competitive advantage").

Empirical work on supply-side complementarities falls into two streams. The first stream infers complementarities from observed adoption patterns of different activities. Cockburn et al. (2000) demonstrated complementarity between research incentives and importance of scientific publications for career advancement. Anand and Khanna (2000) found that firms learned by experience in technology licensing contracts. Novak and Stern (2009) found similar complementarities across decisions to vertically integrate different automobile systems. Gallant et al. (2013a) estimated a dynamic game of generic pharmaceutical manufacturer entry into markets for expiring patented medicines. Complementarities across markets for different products arose due to spillovers of entry on future capabilities (e.g. FDA approvals) and hence to experience in bringing generics to market. Spillovers are modeled as firm specific latent costs depending on past entry decisions. Each entry reduced costs 7\% at the next entry opportunity. Groeger (2013) finds dynamic complementarities in sequential procurement auctions, with participation in an earlier auction affecting future participation.

A second stream examines differences in performance between firms that adopt individual activities versus sets of activities, e.g. Bresnahan et al (2002) studying complementarities in information technology and human capital investment. Related studies of human resource management include 
Ichniowski et al. (1997), and Ichnowski and Shaw (1999). Porter and Siggelkow (2008) noted that there is relatively little research on the degree to which complementarities depend on other choices of the firm.

\section{Complementarity and Market Structure}

Market power embodied in pricing incentives is a first-order consequence of mergers and acquisitions (Farrell and Shapiro 1990). On the demand side, after the Telecommunications Act of 1996, mergers increased the number of distinct programming formats in radio markets (Berry and Waldfogel, 2001), while owners acquiring competing stations tended to differentiate them (Sweeting 2010). Thus choices on firm scope or boundaries complement the product portfolio decision. Costside complementarities also provide a reason, with Jeziorski (2013b) finding savings in operating two stations of the same format, countering the anticompetitive demand effects of mergers. Note that these cost complementarities may arise when producing products that are substitutes on the demand side, potentially leading firms to trade-off differentiation versus complementarity.

Studying the well-known question of whether dominance begets dominance (Chandler v. Schumpeter) Blevins et al. (2013) developed a dynamic oligopolistic model wherein fast food firms chose to expand or contract: size has spillovers on a firms' future outcomes and relative dominance, industry evolution and market structure. In fast food, they found size spillovers on market outcomes, market dominance and structure, with heterogeneity in spillovers. McDonald's had largest spillovers and its ability to retain gains contributed to market dominance.

\section{Empirical Challenges}

There are two major approaches for testing complementarities. The first relies upon the idea that the correlation between two complementary choices is positive, conditional on observable, exogenous factors that might impact performance. The second approach results from the idea that different levels of multiple choices (e.g. high investments in both $R \& D$ and Marketing) may interact to produce superadditive returns.

Athey and Stern (1998) provided a static framework to structure ideas about possibly complementary choices using firm-level choices about organizational decisions. They highlighted the strong assumptions that are required to draw empirical inferences from data using descriptive models. They distinguished between choices and specific sets of choices, e.g. high R\&D and high Marketing investments would denote a "high-high" system. While the distinction is more apparent for discrete choices, the principle applies to continuous choices.

OLS and 2SLS are unbiased only under very restrictive assumptions regarding the nature of the unobservable factors. When there is a choice-specific unobservable that affects productivity, they demonstrate that both OLS and 2SLS provide biased estimates of complementarity effects. The firm is modeled as optimizing over the set of choices, according to a performance measure. It is useful to note that this bias does not even require the presence of system-level unobservables, or even choicespecific unobservables impacting performance. Rather, the unobservables only need to have an effect on adoption of the choice. 
Athey and Stern (1998) provided conditions under which the bias in the estimated complementarity can be signed. When productivity is affected by an unobservable choice-specific shock independently distributed for each choice, both OLS and 2SLS underestimate the true magnitude of complementarity, and may even estimate the wrong sign. If choice-specific shocks are positively correlated across choices, they also showed that there is a fundamental identification problem whereby the inference will indicate positive complementarity where no complementarity (or even negative complementarities) might represent the true condition.

Finally, reduced form models exploiting exclusion restrictions can be used with some confidence with two choices. However, when there are 3 or more choices, such tests may yield estimates of complementarities between a pair of choices even when such choices are substitutes, if there is a third choice that complements one from the pair substitutes for the other one.

\section{Conclusion.}

Complementary choices are prevalent and increasingly important. This paper identified issues that arise in structural estimation of complementary and promising areas for future research. Further progress in these directions will help to explain the determinants of demand complementarities and offer insights about how they affect business strategy and public policy. We might conceptualize the firm as a unique nexus of complementary activities, providing new insights into market structure, competition and regulatory policy.

Allenby, Greg, Geraldine Fennell, Joel Huber, Thomas Eagle, Tim Gilbride, Dan Horsky, Jaehwan Kim, Peter Lenk, Rich Johnson, Elie Ofek, Brian Orme, Thomas Otter, Joan Walker (2005)

"Adjusting Choice Models to Better Predict Market Behavior," Marketing Letters, 16, 3, 197-208.

Anand, Bharat N., Ron Shachar. "Advertising, the matchmaker." The RAND Journal of Economics 42.2 (2011): 205-245.

Anand, Bharat N., Ron Shachar. "(Noisy) communication." Quantitative Marketing and Economics 5.3 (2007): 211-237.

Anand, Bharat N., Tarun Khanna. "Do firms learn to create value? The case of alliances." Strategic management journal 21.3 (2000): 295-315.

Armstrong, M. (2013). A more general theory of commodity bundling. Journal of Economic Theory, $148(2)$.

Athey, Susan, Scott Stern (1998), “An Empirical Framework for Testing Theories About Complementarity in Organizational Design.” Mimeo.

Bajari, Patrick, Benkard, Lanier, Levin, Jonathan (2008), "Estimating Dynamic Models of Imperfect Competition," Econometrica, 75(5), 1331-1370.

Berry, Steven, James Levinsohn and Ariel Pakes (1995), “Automobile Prices in Market Equilibrium," Econometrica, 63(4): 841-890.

Berry, Steven, Amit Gandhi, Philip Haile (2013), "Connected Substitutes and the Invertibility of Demand," Econometrica, 81(5): 2087-2111.

Berry, S. T., Waldfogel, J. (2001). "Do mergers increase product variety? Evidence from radio broadcasting." The Quarterly Journal of Economics, 116(3), 1009-1025.

Bhat, C. 2008. The multiple discrete-continuous extreme value (mdcev) model: Role of utility function parameters, identification considerations, and model extensions. Transportation Research Part B 42 274-303.

Badev, Anton (2013), Discrete games in endogenous networks: Theory and policy. Mimeo. 
Blevins, J, A. Khwaja, N. Yang (2013), "Market Share Dynamics, Size Spillovers and Industry Structure: Evidence from Hamburger Chain Expansion,” Mimeo.

Brandenburger, Adam M., Barry J. Nalebuff. Co-opetition. Random House Digital, 2011.

Bresnahan, T.F., Eric Brynjolfsson, Lorin Hitt (2002), "Information Technology, Workplace Organization, and the Demand for Skilled Labor: Firm-level Evidence," Quarterly Journal of Economics, 117 (1): 339-376.

Chandrasekhar, Arun, Matthew Jackson (2012), "Tractable and consistent exponential random graph models." Mimeo.

Chatain, Olivier. "How Do Strategic Factor Markets Respond to Rivalry in the Product Market?" Strategic Management Journal (2013).

Chan, Tat (2006), "Estimating a Continuous Hedonic Choice Model with an Application to Demand for Soft Drinks," RAND Journal of Economics, 37 (2).

Ching, Andrew, Susumu Imai, Neelam Jain (2009), Bayesian Estimation of Dynamic Discrete Choice Models, Econometrica, vol. 77(6), pp.1865-1899.

Christakis, Nicholas, James Fowler, Guido W. Imbens, Karthik Kalyanaraman (2010), “An empirical model for strategic network formation." Mimeo.

Cockburn, Iain, Rebecca Henderson, Scott Stern (2000), "Untangling the Origins of Competitive Advantage," Strategic Management Journal, 21(10-11): 1123-1145.

Crawford, Gregory S., Ali Yurukoglu (2012), "The Welfare Effects of Bundling in Multichannel Television Markets," American Economic Review, 102(2): 643-685.

DePaula, Aureo, Seth Richards-Shubik, Elie Tamer (2011), Inference approaches with network data, mimeo.

Derdenger, Timothy, Vineet Kumar (2013), “The Dynamic Effects of Bundling as a Product Strategy," Marketing Science, 32(6): 827-859.

Derdenger, T., X. Liu, B. Sun. (2013) An Empirical Analysis of Consumer Purchase Behavior of Base Products and Add-ons Given Compatibility Constraint. Mimeo, Carnegie Mellon University.

Farrell, J., \& Shapiro, C. (1990). Horizontal mergers: an equilibrium analysis. The American Economic Review, 107-126.

Figurelli, L. (2012). Store choice in spatially differentiated markets Working Paper.

Fong, Kyna, Robin Lee (2012), "Markov-Perfect Network Formation: An Applied Framework for Bilateral Oligopoly and Bargaining in Buyer-Seller Networks." Mimeo.

Gallant, R., H. Hong, A. Khwaja (2013a), "The Dynamic Spillovers of Entry: An Application to the Generic Drug Industry.” Mimeo.

Gallant, R., H. Hong,, A. Khwaja (2013b), "Bayesian Estimation of a Dynamic Game with Endogenous, Partially Observed, Serially Correlated State.” Mimeo.

Gentzkow, M. 2007. Valuing new goods in a model with complementarities: Online newspapers. American Economic Review 97(3) 713-744.

Goldsmith-Pinkham, Paul, Guido W. Imbens (forthcoming), "Social networks and the identification of peer effects," Journal of Business and Economic Statistics.

Groeger, J. (2012). A Study of Participation in Dynamic Auctions. Carnegie Mellon University Working Paper.

Hanemann, W. Michael (1984). Discrete/Continuous Models of Demand. Econometrica, 52, 3, 541561.

Hsieh, Chih-Sheng, Lung-Fei Lee (2013), A structural modeling approach for network formation and social interactions with applications to students' friendship choices and selectivity on activities. Mimeo.

Huang, G., A. Khwaja, K. Sudhir (2012), "Short Run Needs and Long Term Goals: A Dynamic Model of Thirst Management." Mimeo. 
Ichniowski, Casey, Kathryn Shaw, Giovanna Prennushi (1997), "The Effects of Human Resource Management Practices on Productivity: A Study of Steel Finishing Lines," The American Economic Review, 87(3): 291-313.

Ichniowski, Casey, Kathryn Shaw (1999), "The Effects of Human Resource Systems on Productivity: An International Comparison of U.S. and Japanese Plants," Management Science, 45(5): 704-722. Imbens, G., B. Graham, G. Ridder (2010), "Complementarity and Aggregate Implications of Assortative Matching: A Nonparametric Analysis.” Mimeo.

Jackson, Matthew O. (2008), Social and Economics Networks, Princeton.

Jeziorski (2013a). Effects of mergers in two-sided markets: Examination of the U.S. radio industry, Mimeo.

Jeziorski (2013b). Estimation of cost synergies from mergers: Application to U.S. Radio, mimeo

Jeziorski (2013c). Empirical Model of Dynamic Merger Enforcement - Choosing Ownership Caps in U.S. Radio, Mimeo.

Kauffman, Stuart A. (1993). The Origins of Order: Self-Organization and Selection in Evolution. Oxford University Press.

Khwaja, A. (2013), "Investment in Human Capital, Longevity and Moral Hazard in a Stochastic Life-Cycle Model of Demand for Health," Mimeo.

Khwaja, A. (2010), "Estimating Willingness to Pay for Medicare Using a Dynamic Life-Cycle Model of Demand for Health Insurance," Journal of Econometrics, 156, 130-147.

Kim, Jaehwan, Greg M. Allenby, Peter E. Rossi. 2002. Modeling consumer demand for variety. Marketing Science 21(3) 229-250.

Lee, S., J. Kim, G. M. Allenby. 2013. A Direct Utility Model for Asymmetric Complements. Marketing Science.

Lee, Sanghak, G.M.Allenby. 2013. Modeling Indivisible Demand, mimeo, Ohio State University.

Lee, C., V. Kumar, S. Gupta (2013) Designing Freemium: a Model of Consumer Usage, Upgrade, and Referral Dynamics, Mimeo.

Leung, Michael (2013), Two-step estimation of network formation models with incomplete information, mimeo.

Liu, Hongju, Pradeep K. Chintagunta, Ting Zhu. "Complementarities and the demand for home broadband internet services." Marketing Science 29.4 (2010): 701-720.

Manchanda, Puneet, Asim Ansari, Sunil Gupta (1999), "The 'Shopping Basket': A Model for MultiCategory Purchase Incidence Decisions," Marketing Science, 18, 95-114.

Mele, Angelo (2012), “A Structural Model of Segregation in Social Networks," Mimeo.

Milgrom, Paul, John Roberts (1990), "Rationalizability, Learning, and Equilibrium in Games with Strategic Complementarities," Econometrica, 58 (6): 1255-1277.

Milgrom, Paul, Roberts, John, (1990). "The Economics of Modern Manufacturing: Technology, Strategy, and Organization," American Economic Review, 80(3), 511-528

Miyauchi, Yuhei (2012), Structural estimation of a pairwise stable network formation with nonnegative externality, Mimeo

Musalem, Andres, Wilbur, Kenneth C., Del Sol, Patricio (2013), "A Parsimonious Structural Model of Individual Demand for Multiple Related Goods," Mimeo.

Norets, Andriy (2009), "Inference in dynamic discrete choice models with serially correlated unobserved state variables," Econometrica 77(5), 1665-1682.

Novak, Sharon, Scott Stern (2009), "Complementarity Among Vertical Integration Decisions: Evidence from Automobile Product Development," Management Science, 55(2): 311-332.

Pakes, A. (2010). Alternative models for moment inequalities. Econometrica, 78(6), 1783-1822.

Park, M., Town, R. (2012) "New Evidence on the Relationship between Managed Care and Hospital Consolidation." Mimeo. 
Porter, Michael E. (1996), "What Is Strategy,” Harvard Business Review, November-December, 6178

Porter, Michael E., Nicolaj Siggelkow (2008), "Contextual Interactions within Activity Systems and Sustainability of Competitive Advantage," Academy of Management Perspectives, 22(2): 34-56.

Rossi, Peter E., Greg M. Allenby, Robert McCulloch (2005) Bayesian Statistics and Marketing, John Wiley \& Sons.

Sato, K. 1967. A two-level constant-elasticity-of-substitution production function. The Review of Economic Studies 34 201-218.

Satomura, Takuya, Jaehwan Kim, Greg M. Allenby (2011) "Multiple Constraint Choice Models with Corner and Interior Solutions," Marketing Science, 30, 3, 481-490.

Sheng, Shuyang (2012), Identification and estimation of network formation games, mimeo

Shy, Oz (2011), "A Short survey of network economics", Review of Industrial Organization, 38(2):119-149

Song, Inseong, Pradeep K. Chintagunta. 2007. A discrete-continuous model for multicategory purchase behavior of households. Journal of Marketing Research 44(4) 595-612.

Sriram, S., Pradeep K. Chintagunta, Manoj K. Agarwal (2010). "Investigating consumer purchase behavior in related technology product categories." Marketing Science, 29 (2): 291-314.

Sweeting, A. (2010). The effects of mergers on product positioning: evidence from the music radio industry. The RAND Journal of Economics, 41(2), 372-397.

Vásquez, Felipe, Michael Hanemann. 2008. Functional forms in discrete/continuous choice models with general corner solution. Mimeo. 